\title{
Evaluation of differential disaccharide excretion in urine for non-invasive investigation of altered intestinal disaccharidase activity caused by $\alpha$-glucosidase inhibition, primary hypolactasia, and coeliac disease
}

\author{
I Bjarnason, R Batt, S Catt, A Macpherson, D Maxton, I S Menzies
}

Department of Clinical Biochemistry and Medicine,

King's College School of Medicine,

London

I Bjarnason

A Macpherson

I S Menzies

Department of Small Animal Medicine and Surgery, The Royal Veterinary College, University of London R Batt

Department of Chemical Pathology, St Thomas's Hospital Medical School, London

$S$ Catt

D Maxton

Correspondence to: Dr I Bjarnason, Department of Clinical Biochemistry, King's College School of Medicine and Dentistry, Bessemer Road, London SE5 9PJ.

Accepted for publication 9 May 1996

\begin{abstract}
Background/Aim-The reliability of a quantitative method for the non-invasive assessment of intestinal disaccharide hydrolysis was assessed.

Methods-Differential excretion of intact disaccharide, expressed as ratios of lactulose to appropriate hydrolysable disaccharides in urine collected following combined ingestion, has been investigated in healthy volunteers with drug induced $\alpha$-glucosidase inhibition, in subjects with primary hypolactasia, and patients with coeliac disease.

Results-Oral administration of the $\alpha$-glucosidase inhibitor 'Acarbose' (BAY g 5421, $200 \mathrm{mg}$ ) together with sucrose and lactulose increased the urinary sucrose/ lactulose excretion ratios (\% dose/10 h) fivefold. The effect was quantitatively reproducible, a higher dose of 'Acarbose' (500 $\mathrm{mg}$ ) increasing the excretion ratio to about $1 \cdot 0$ indicating complete inhibition of intestinal sucrase activity. The suitability of the method for measuring differences in dose/response and duration of action was assessed by comparing three different $\alpha$-glucosidase inhibitors (BAY $g$ 5421, BAY m 1099, and BAY o 1248) and found to be satisfactory. Subjects with primary adult hypolactasia had urine lactose/ lactulose excretion ratios raised to values indicating reduced rather than complete absence of lactase activity whereas sucrose/lactulose ratios were not significantly affected. 'Whole' intestinal disaccharidase activity assessed by this method demonstrated impairment of lactase, sucrase, and isomaltase in eight, one, and seven, respectively, of 20 patients with coeliac disease. By contrast in vitro assay of jejunal biopsy tissue indicated pandisaccharidase deficiency in all but five of these patients. This shows the importance of distinguishing between 'local' and 'whole' intestinal performance.
\end{abstract}

Conclusions-Differential urinary excretion of ingested disaccharides provides a reliable, quantitative, and non-invasive technique for assessing profiles of intestinal disaccharidase activity.

(Gut 1996; 39: 374-381)

Keywords: coeliac disease, intestinal function, intestinal disaccharidases, intestinal permeability.
Intestinal disaccharidase deficiency, either primary or secondary, is a frequent cause of gastrointestinal symptoms and it is reported that as many as $50 \%$ to $90 \%$ of adult non-white subjects may be lactase deficient. ${ }^{1-3}$ Conventional non-invasive assessment of intestinal disaccharidase deficiency is open to some criticism. The oral lactose tolerance test entails ingestion of non-physiological quantities of lactose (50-100 g, equivalent to 1-2 litres of milk) or other disaccharide, often accompanied by unpleasant symptoms. ${ }^{4}$ The test has a high false positive rate, thus a rise in blood glucose below $20 \mathrm{mg} / 100 \mathrm{ml}(1 \cdot 1 \mathrm{mmol} / \mathrm{l})$, which is taken to indicate disaccharidase deficiency ${ }^{4}$ may have alternative explanations. The high false positive rate can be reduced somewhat by intra-duodenal instillation of disaccharide but at the cost of losing the non-invasive nature of the procedure. ${ }^{5}$ Alternatively, with respect to hydrolysis of lactose, it has been suggested that measurement of the rise of blood galactose might be preferable to that of glucose. ${ }^{6}$ Furthermore, as renal excretion of galactose is efficient, some authors have advocated the measurement of galactose, or of a lactose/ galactose ratio, in urine after ingestion of lactose. ${ }^{78}$ Methods involving breath hydrogen or ${ }^{14} \mathrm{C}$-labelled carbon dioxide after ingestion of appropriate disaccharide test doses ${ }^{5910}$ are beset with somewhat similar problems. Difficulties with these techniques are in part because the uptake and metabolism of monosaccharide products, or generation of hydrogen in the bowel depend upon several other variable factors beside the rate of hydrolysis by brush border disaccharidases. ${ }^{11-13}$

Diagnosis of disaccharidase deficiency can also be made by in vitro assay of homogenised jejunal tissue. It is necessary to consider, however, how well these assays represent the in vivo performance of the whole intestine, especially in coeliac disease where the severity of the disease is usually maximal in the proximal jejunum, ${ }^{14}$ ileal functions being comparatively unaffected.

A further non-invasive technique has been proposed that avoids error due to variations in monosaccharide transport and metabolism, and may therefore permit a more specific and quantitative assessment of intestinal disaccharidase activity. ${ }^{11} 1215$ The principle of this method, which entails measurement of the renal excretion of several disaccharides 
following their combined ingestion, is based on the finding that recovery of intact disaccharide in urine after ingestion is inversely related to the rate of their intestinal hydrolysis. The test solution contains a non-hydrolysable 'reference' disaccharide (for example, lactulose) together with hydrolysable disaccharides (lactose, sucrose, palatinose). As renal excretion of these disaccharides after entering the circulation is known to be complete, without metabolic loss, the excretion ratios of hydrolysable/

Variables

Delivery

\begin{tabular}{|c|c|c|c|}
\hline 1 Content of test solution & $\begin{array}{ll}\text { Lactose } & 10 \mathrm{~g} \\
\text { Sucrose } & 10 \mathrm{~g} \\
\text { Palatinose } & 10 \mathrm{~g}\end{array}$ & $\begin{array}{l}\text { Lactulose } \\
\quad 6.7 \mathrm{~g}\end{array}$ & $\begin{array}{c}\text { L-Rhamnose } \\
1.0 \mathrm{~g}\end{array}$ \\
\hline \multicolumn{4}{|l|}{2 Ingestion/regurgitation } \\
\hline \multicolumn{4}{|l|}{3 Gastric emptying } \\
\hline \multicolumn{4}{|c|}{ Digestion } \\
\hline \multicolumn{4}{|c|}{4 Hydrolysis by disaccharidases } \\
\hline \multicolumn{4}{|l|}{ testinal permeation } \\
\hline \multicolumn{4}{|l|}{5 Dilution by secretions } \\
\hline \multicolumn{4}{|l|}{6 Rate of transit } \\
\hline \multicolumn{4}{|l|}{7 Mucosal area } \\
\hline \multicolumn{4}{|l|}{8 Mucosal permeabillity } \\
\hline \multicolumn{4}{|c|}{ isposal } \\
\hline \multicolumn{4}{|l|}{9 Metabolism } \\
\hline \multicolumn{4}{|l|}{10 Renal clearance } \\
\hline \multicolumn{4}{|l|}{11 Urine collection } \\
\hline \multicolumn{4}{|c|}{ nterpretation of urinary ratios } \\
\hline Lactase activity & \multicolumn{2}{|c|}{ LAC/LACL } & \\
\hline Sucrase activity & \multicolumn{2}{|c|}{ SUC/LACL } & \\
\hline Isomaltase activity & \multicolumn{2}{|c|}{ PAL/LACL } & \\
\hline Mucosal permeability & & LAC & /RHAM \\
\hline
\end{tabular}

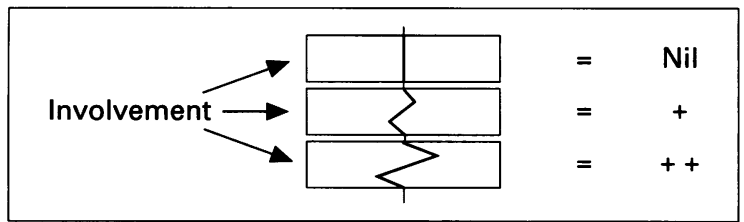

Figure 1: Principle of the differential urine excretion of orally administered test substances. The precise quantity of intact disaccharide passing by unmediated diffusion across the intestinal mucosa into the circulation is determinted by the factors shown in the Figure. The inclusion of lactulose, which resists the action of intestinal hydrolases in a test solution containing hydrolysable disaccharides (lactose, sucrose or palatinose either individually or in combination), enables a correction for most non-mucosal variables on urinary excretion to be obtained. These four disaccharides permeate the intestine as intact molecules by $a$ common mucosal pathway in quantities that depend upon their individual concentrations within the intestine. In turn, these concentrations are determined by the efficiency of hydrolysis by appropriate disaccharidases. As lactulose will be affected in the same way as the 'test' disaccharides by all these factors except for the activity of mucosal disaccharidase, which this disaccharide resists, the urinary excretion ratios of lactose, sucrose, or palatinose, or all three, to lactulose can be regarded as specific indices of the efficiency with which the concentrations of lactose, sucrose, and palatinose are reduced by hydrolysis within the small intestine. In the absence of hydrolysis of lactose the fraction of the ingested dose permeating the intestine will approach that of lactulose (which resists hydrolysis) so that the lactosel lactulose ratio of percentages of the oral dose excreted in urine would be $1 \cdot 0$. With normal (active) intestinal hydrolysis of lactose this ratio is much lower, usually between $0 \cdot 1-0 \cdot 3$, and intermediate valus provide a quantitative measure of the degree of impaired hydrolysis. Nil $=$ No effect. $+=$ Plays $a$ part in the overall urine excretion of the test substance but the effect on simultaneously ingested test substances is equal. $++=$ Plays a part in the overall urine excretion of the test substance but the effect on simultaneously ingested test substances differs. non-hydrolysable disaccharide should relate inversely to the activity of intestinal disaccharides (lactase, sucrase and, in the case of palatinose, isomaltase)..$^{11} 1215$ This technique has been used to demonstrate lactase deficiency associated with rotaviral infection and combined sucrase and isomaltase deficiency in asucrasia. ${ }^{11} 1215$ The main purpose of this study was further evaluation of the reliability of the urine disaccharide ratio technique for both clinical and research purposes. This has been undertaken by assessing the ability of the differential disaccharide excretion technique to distinguish the differences in dose/response and duration of action of three orally administered $\alpha$-glucosidase inhibitors and, secondly, to quantitate intestinal lactase activity in subjects with confirmed genetic hypolactasia (primary adult hypolactasia). Intestinal disaccharide hydrolysis assessed in vivo by the combined disaccharide ratio test was also compared with in vitro assay of disaccharidase activity in homogenised jejunal biopsy tissue in patients with coeliac disease to study the effect of a disorder that mainly involves the jejunum.

\section{Methods}

DIFFERENTIAL URINARY EXCRETION OF INGESTED DISACCHARIDES: PRINCIPLES INVOLVED

The principle of the differential urinary excretion of ingested sugar probes has been detailed elsewhere. ${ }^{13}{ }^{16}$ Figure 1 briefly outlines the principle and how urinary excretion ratios of a non-hydrolysable disaccharide and hydrolysable disaccharides can give quantitative information of the rate of intestinal hydrolysis of some disaccharides.

STUDIES WITH $\alpha$-GLUCOSIDASE INHIBITORS Fourteen healthy adult white volunteers were studied. A strict sucrose free diet was implemented 18 hours before and throughout the test period. After an overnight fast each subject voided urine directly before the test to confirm absence of sucrose. At 8 am the test solution containing $20 \mathrm{~g}$ sucrose ( $\alpha-\mathrm{D}$-glucopyranosyl $\beta$-D-fructofuranoside) and $6.7 \mathrm{~g}$ lactulose $(\beta 1-4$ galactopyranosyl-fructose $=10 \quad \mathrm{ml}$ 'Duphalac' lactulose syrup, Duphar Laboratories, Southampton) dissolved in $300 \mathrm{ml}$ water $(300 \mathrm{mmol} / \mathrm{l})$ was ingested within a period of four minutes. Food and fluids were not permitted until 2.5 hours later. A complete urine collection was made from 8 am to $6 \mathrm{pm}$ (10 hours), the volume recorded, and an aliquot preserved with merthiolate $(10 \mathrm{mg} / 100$ $\mathrm{ml}$ minimum) for analysis of sugars by quantitative paper or thin layer chromatography. ${ }^{11} 1718$ Results are expressed as urinary sucrose/lactulose ratios of percentages of the oral doses excreted during 10 hours.

\section{Dose/response studies}

To evaluate the reliability of the method for the quantitative differentiation of intestinal 
disaccharidase activity a study of the effect of different dose levels of a known $\alpha$-glucosidase inhibitory drug (BAY g 5421, 'Acarbose') was undertaken. Subjects underwent a control test without $\alpha$-glucosidase inhibition $(n=14)$, which was then repeated (with intervals of at least one week) adding either BAY g 5421 (Acarbose:

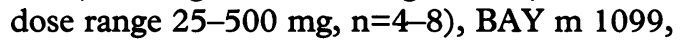
(dose $100 \mathrm{mg}, \mathrm{n}=7$ ) or BAY o 1248 (dose 10 $\mathrm{mg}, \mathrm{n}=6$ ) to the test solution. One subject underwent 13 tests with BAY $\mathrm{g} 5421$ in the dose range $0-500 \mathrm{mg}$ added to a test solution that contained lactose ( $\beta-1-4-D$-galactopyranosyl- $\alpha$-D-glucose) $20 \mathrm{~g}$ in addition to sucrose $20 \mathrm{~g}$ and lactulose $6.7 \mathrm{~g}$ dissolved in $300 \mathrm{ml}$ drinking water, to assess response in relation to both sucrose and lactose hydrolysis.

\section{Duration of action}

To demonstrate the ability of the method to resolve differences in the duration of disaccharidase inhibition the action of the three $\alpha$-glucosidase inhibitors on intestinal sucrose hydrolysis over a timed period was also assessed in a single individual as follows: (a) BAY g 5421 ('Acarbose' $500 \mathrm{mg}$ ) with, and then $30,60,120$ minutes and 48 hours before oral administration of the test solution. (b) BAY m 1099 (200 mg) with, and then 30, 60, 120 minutes and 48 hours before the test solution. (c) BAY o $1248(20 \mathrm{mg})$ with, and then $60,120,180$ minutes and 48 hours before the test solution.

INVESTIGATION OF SUBJECTS WITH PRIMARY (GENETIC) ADULT HYPOLACTASIA

Twenty three adult white volunteers acted as normolactasic control subjects, 16 Asian or Afro-Caribbean together with two white subjects comprised the hypolactasic group. Hypolactasia was independently established by demonstrating a positive conventional lactose tolerance test (blood glucose rise $<20 \mathrm{mg} / 100$ $\mathrm{ml}$ and a diarrhoeal response after ingestion of $50 \mathrm{~g}$ lactose) and absence of intestinal disease apart from milk intolerance. A lactose and sucrose free diet was implemented 18 hours before, and throughout, each test. After an overnight fast each subject collected a baseline urine sample, which ensures that errors of interpretation due to inadequate dietary restriction, unsuspected lactulose medication, endogenous lactosuria of pregnancy, etc, are avoided. Patients then ingested a test solution containing lactose $(20 \mathrm{~g})$ sucrose $(20 \mathrm{~g})$ and lactulose $(6.7 \mathrm{~g})$ dissolved in $300 \mathrm{ml}$ water. A complete urine collection was then made in two consecutive five hour periods (that is, $0-5$ hours and 5-10 hours). The urine volumes were recorded and aliquots preserved $(10 \mathrm{mg}$ merthiolate $/ 100 \mathrm{ml}$ minimum) for quantitative analysis of lactose, sucrose, lactulose, and galactose by quantitative paper chromatography or an adaptation of this method to thin layer chromatography. ${ }^{11} 1718$ Results were expressed as percentage of the dose of each sugar excreted in urine during $0-5$ or $0-10$ hour period and as lactose-sucrose/lactulose ratios (of percentages excreted). Lactose/ galactose urine excretion ratios were also calculated to assess whether this ratio gave a better discrimination of hypolactasic from normolactasic subjects than lactose or galactose alone as has previously been suggested. $^{78}$

\section{INVESTIGATION OF PATIENTS WITH COELIAC} DISEASE

Nineteen patients undergoing jejunal biopsy as a part of routine gastrointestinal investigation, in whom jejunal histology was normal and significant intestinal pathology not discovered, served as a control group. The mean age of this group was 41 years (range 21-67 years).

Eleven patients with symptomatic, untreated, and nine with treated coeliac diseases were studied, the latter having achieved a full clinical recovery with a gluten free diet of mean duration six years (range nine months-12 years). The mean age of the whole group was 54 years (range 28-74). Each patient was admitted to a metabolic research ward for investigation, in vivo studies and jejunal biopsies being performed within a week of each other.

\section{Assessment of intestinal disaccharide hydrolysis by} urinary excretion ratio

Dietary sources of sucrose, lactose, and lactulose were excluded for 18 hours before and throughout the test period. Each subject fasted overnight and voided urine directly before the test, a 'baseline' urine being retained to exclude the presence of disacchariduria. At 8 am each subject ingested a $300 \mathrm{ml}$ test solution containing: Lactose: $10 \mathrm{~g}$ (to assess lactase activity), Sucrose: $10 \mathrm{~g}$ (to assess sucrase activity), Palatinose: $10 \mathrm{~g}$ (to assess palatinase (isomaltase) activity ( $\alpha-1-6 \mathrm{D}$ glucopyranosylD-fructofuranose, isomaltulose), Lactulose: $6.7 \mathrm{~g}$ (as non-hydrolysable reference for disaccharide permeation, also to assess 'large pore' permeation), L-rhamnose: $1 \mathrm{~g}$ (to assess 'small pore' permeability).

Incorporation of L-rhamnose permits simultaneous assessment of intestinal permeability by measurement of lactulose-/L-rhamnose urine excretion ratios, but as the data from this study did not expand on the already extensive published literature these results are not presented. ${ }^{13}$

Foods and fluids were permitted 2.5 hours after ingestion of the test solution.

Urine was collected for $0-5$ and 5-10 hours, with merthiolate $(10 \mathrm{mg} / 100 \mathrm{ml})$ as a preservative, for marker analysis as described. ${ }^{17} 18$

Assessment of intestinal disaccharide activity by in vitro assay

Intestinal biopsy specimens were obtained by intubation technique with an adult Watson biopsy capsule, under radiological guidance, just distal to the ligament of Trietz. A portion of the biopsy specimen was allocated for histological examination, the remainder being 


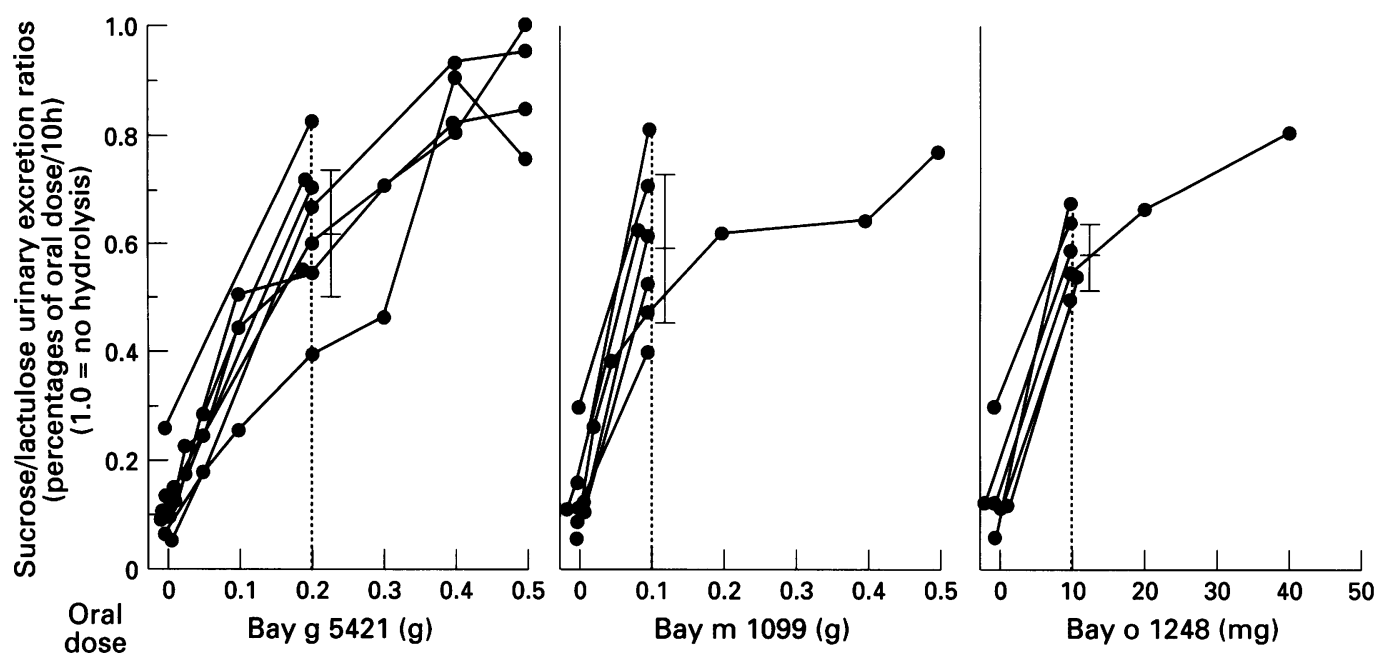

Figure 2: Use of the disaccharide ratio method to compare the dose/response relation of three different $\alpha$-glucosidase inhibitors on intestinal sucrose hydrolysis. This is assessed by measuring the excretion ratio of sucrosellactulose (\% dose in a 10 hour urine collection) following ingestion of the disaccharide test solution together with increasing dose of $B A Y g 5421$ (Acarbose), BAY $m$ 1099, and BAY o 1248. Equivalent effects were produced by $0.2 \mathrm{~g}, 0.1 \mathrm{~g}$, and $10 \mathrm{mg}$ doses of these inhibitors, respectively.

'flash' frozen in liquid nitrogen and stored at $-70^{\circ} \mathrm{C}$. No more than two minutes lapsed between firing the capsule and freezing the samples. Lactase and sucrase activities in homogenised biopsy tissue were measured by a micro-assay as described previously. ${ }^{19}$ The same method was used for measurement of isomaltase activities using palatinose as the substrate, dissolving $0.056 \mathrm{~mol} /$ litre in $0.1 \mathrm{M}$ sodium maleate buffer, $\mathrm{pH} 6 \cdot 0$. Enzyme units were expressed as units/mg protein. All subjects gave informed consent and the studies were approved by the Harrow Health Authority and St Thomas's Hospital Ethical Committee.

STATISTICS

Statistical difference between sequential data were assessed by the paired Student $t$ test, otherwise Wilcoxon's rank sum test was used.

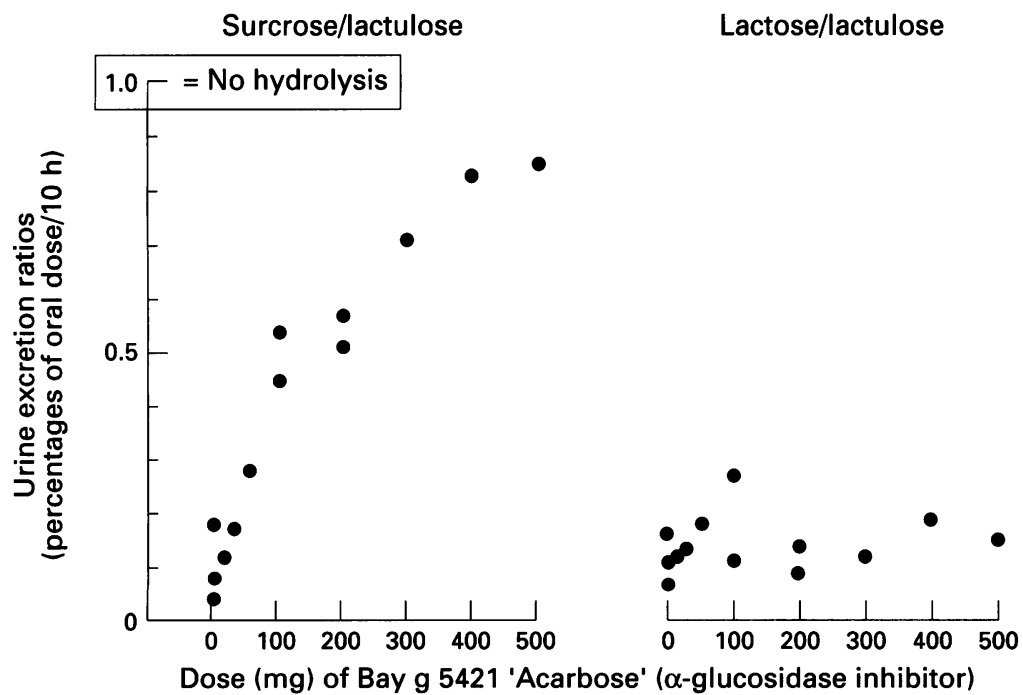

Figure 3: Dose response to the $\alpha$-glucosidase inhibitor BAYg 5421 (Acarbose). Ten hour urinary disaccharide excretion recorded from a single volunteer in response to co-ingestion of sucrosellactose/lactulose test solution together with nine different dose levels of BAY g 5421 . This shows a steady rise in the sucroselactulose ratio as the oral dose is increased, confirming that the action of the inhibitor on intestinal sucrase activity is dose dependent. Absence of a significant change in the lactoselactulose excretion ratio is evidence of the specificity of inhibitory action.

\section{Results}

STUDIES WITH $\alpha$-GLUCOSIDASE INHIBITORS

Figure 2 shows the 10 hour urine sucrose/ lactulose excretion ratios obtained when the test solution had been ingested without, and then together with progressively increasing doses of the three $\alpha$-glucosidase inhibitors. The normal control 10 hour sucrose/lactulose excretion ratio (mean SD)) was $0 \cdot 12(0 \cdot 10)$, range $0 \cdot 05-0 \cdot 30$ ).

With increasing amounts of simultaneously ingested BAY g 5421 (Acarbose 25-500 mg) there was stepwise and significant $(p<0.01)$ increase in urine excretion ratio of sucrose/ lactulose with a mean of $0.61(0.12)$ and 0.91 $(0.09)$ for 200 and $500 \mathrm{mg}$ BAY g 5421, respectively. Ingestion of the two other $\alpha$-glucosidase inhibitors also produced a significant $(p<0.01)$ rise in urinary sucrose/lactulose excretion ratios. The relation between dose and response was very different, approximately similar effects being produced by $200 \mathrm{mg}$ BAY g 5421, $100 \mathrm{mg} \mathrm{BAY} \mathrm{m} \mathrm{1099,} \mathrm{and} 10 \mathrm{mg}$ BAY 01248 , giving mean sucrose/lactulose ratios of $0.61(0.12), 0.58(0.13)$, and $0.55(0.08)$, respectively (see Fig 2 ).

Figure 3 shows sucrose/lactulose and lactose/lactulose responses obtained from a single subject receiving nine dose levels of BAY g 5421 (range $10-500 \mathrm{mg}$ ). The progressive rise in the sucrose/lactulose excretion ratio shows satisfactory resolution between different levels of $\alpha$-glucosidase inhibition while absence of a significant change in lactose/lactulose excretion ratio provides evidence of specificity.

Figure 4 shows the rate at which the $\alpha$-glucosidase inhibitory action of the three drugs declines. Whereas the sucrose/lactulose excretion ratio after ingestion of BAT g 5421 and BAY $m 1099$ fall off rapidly, reaching 30\% of the initial value when the test dose is delayed by 30 minutes, the effect of BAY o 1248 is more prolonged, taking three hours to reach the $30 \%$ level. The resolution obtained seems to be satisfactory for investigating the duration of action of such drugs. 


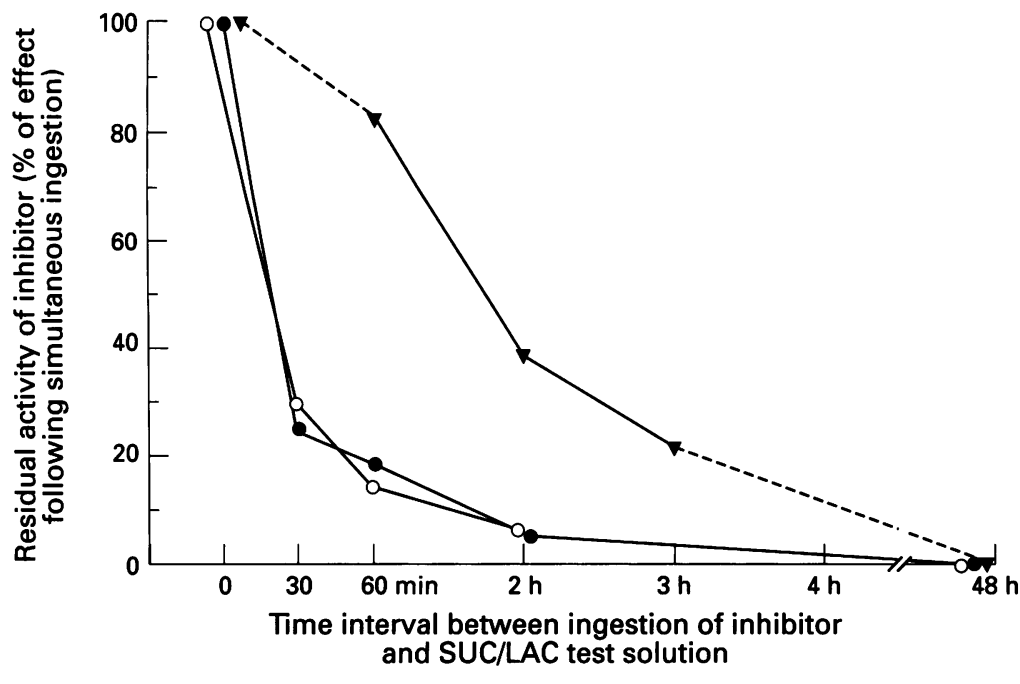

Figure 4: Use of the differential disaccharide excretion method to compare short-time duration of different $\alpha$-glucosidase inhibitors on intestinal sucrase activity. Equivalent doses of $B A Y g 5421$ (open circles), BAY 1099 (closed circles), and BAY o 1248 (closed triangles) were ingested by a single volunteer at the same time as and, on separate occasions, 30, 60 minutes and two, three, and 48 hours before, oral administration of the disaccharide test solution. A 100\% 'inhibition' score was allocated to the sucroselactulose excretion ratio obtained following simultaneous administration of test solution and inhibitor, and changes in drug action seen after the lapse of different periods of time were expressed as that fraction of the initial dose that would be required to produce the observed sucrosellactulose ratio if it had been given simultaneously with the test solution. The latter value was calculated by extrapolation from graph relating dose response for each inhibitor from the same subject.

GENETICALLY DETERMINED HYPOLACTASIA

Ten hour urine excretions of lactulose, lactose, sucrose, and galactose and the calculated lactose-sucrose/lactulose and lactose/galactose of two groups of healthy subjects, one with normal intestinal lactase and the other with genetically determined hypolactasia, are shown in Figure 5. The five hour urinary data (not shown) showed less discrimination between normal controls and hypolactasic subjects. Subjects with hypolactasia excreted significantly $(p<0.01)$ more lactose and less galactose than those with active intestinal lactase activity. Sucrose excretion did not differ significantly between the groups and, although lactulose excretion was less in hypolactasic subjects, this did not reach a statistical significance. The 10 hour urinary excretion ratio of lactose/ lactulose differed significantly between the groups and none of the 18 subjects defined as hypolactasic by other criteria had a ratio that was below the mean (2 SD) $(0.24)$ for the normolactasic group. Alternatively, although the discrimination of hypolactasic subjects by excretion of lactose or galactose is incomplete in 10 hour urine samples, combination of these measurements, which respond to reduced lactase activity in opposite directions, as lactose/galactose excretion ratios provides almost complete discrimination. Sucrose/lactulose ratios in Figure 5 show that eight of the hypolactasic subjects have higher values than any of the normolactasic subjects, which could suggest a coexistent impairment of sucrose hydrolysis. However, this seems to be the outcome of a decrease in lactulose rather than an increase in sucrose excretion, and more likely to be the consequence of osmotic accumulation of fluid due to retention of unabsorbed lactose (due to hypolactasia) in the intestine, lactulose permeation being reduced by the resulting dilution and hurry. ${ }^{20}$ Sucrose uptake would not be affected to the same extent because, unlike lactulose, it is largely hydrolysed before reaching the lower part of the small intestine where these osmoticaly induced effects are most pronounced.

\section{DISACCHARIDE HYDROLYSIS IN PATIENTS WITH COELIAC DISEASE}

Non-invasive in vivo assessment

Figure 6 shows the 10 hour urinary excretion of the four disaccharides and the calculated lactose/

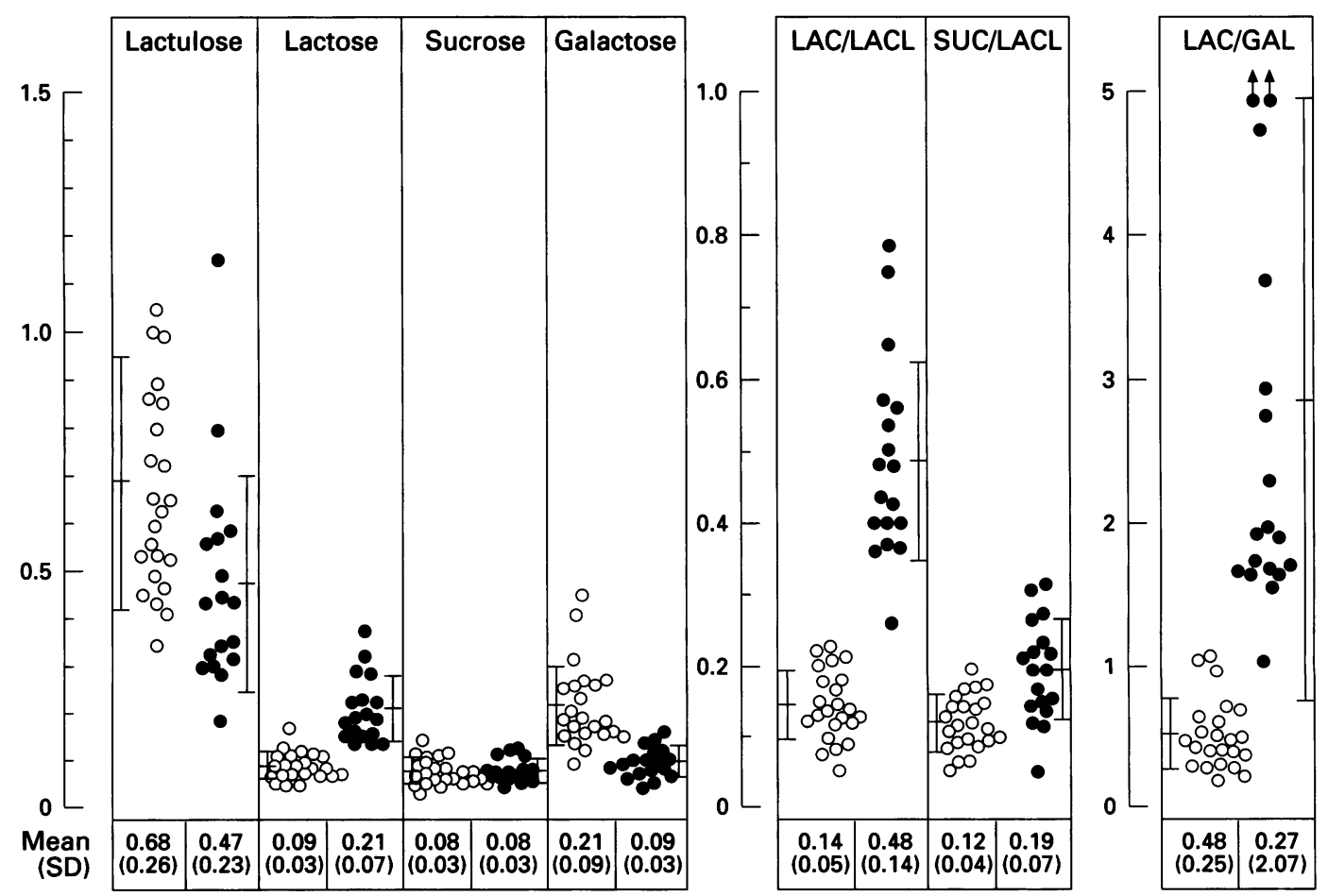

Figure 5: Ten hour urine excretion (\% dose) of lactulose, lactose, sucrose, and galactose and the lactose-sucrosellactulose and lactose/galactose urine excretion ratios in normolactasic (open circles) and hypolactasic (filled circles) subjects after an oral test solution containing lactose $(20 \mathrm{~g})$, sucrose $(20 \mathrm{~g})$, and lactulose $(6 \cdot 7 \mathrm{~g})$. 


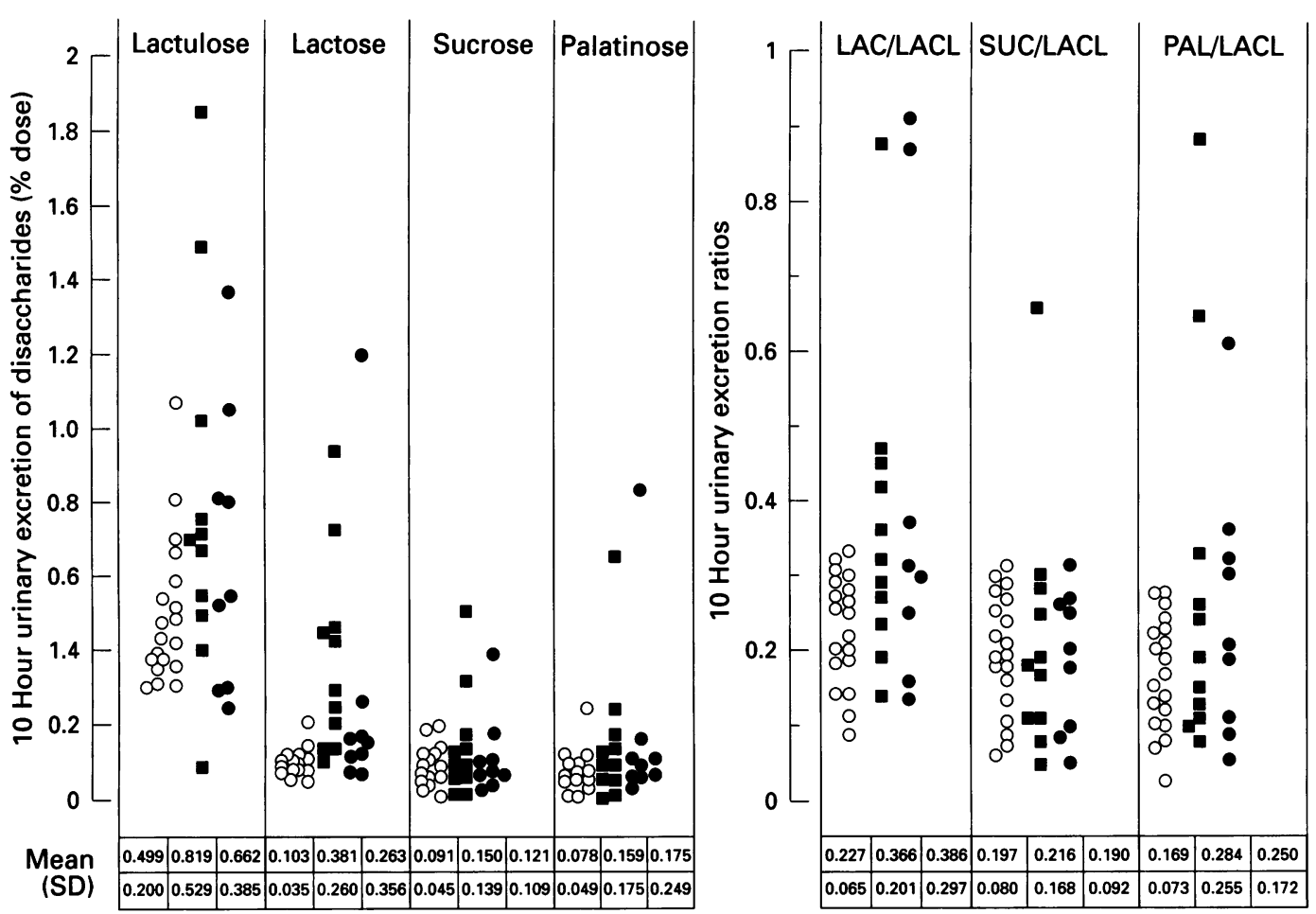

Figure 6: Ten hour urine excretion of disaccharides and ratios of lactose-sucrose-palatinosellactulose from controls (open circles), untreated (filled boxes), and treated (filled circles) patients with coeliac disease.

lactulose, sucrose/lactulose, and palatinose/ lactulose excretion ratios from patients without gastrointestinal disease and patients with untreated and treated coeliac disease. Only the differential urinary excretion of lactose/lactulose from patients with untreated coeliac disease differed significantly $(p=0 \cdot 047)$ from controls. Eight, one and seven of the coeliac group were found to have varying degrees of defective lactose, sucrose, and palatinose hydrolysis, respectively. The five hour urinary data showed less discrimination (data not shown) between controls and patients with coeliac disease.

In vitro assay of jejunal biopsy tissue

Figure 7 shows the in vitro lactase, sucrase, and palatinase (isomaltase) activities. The control
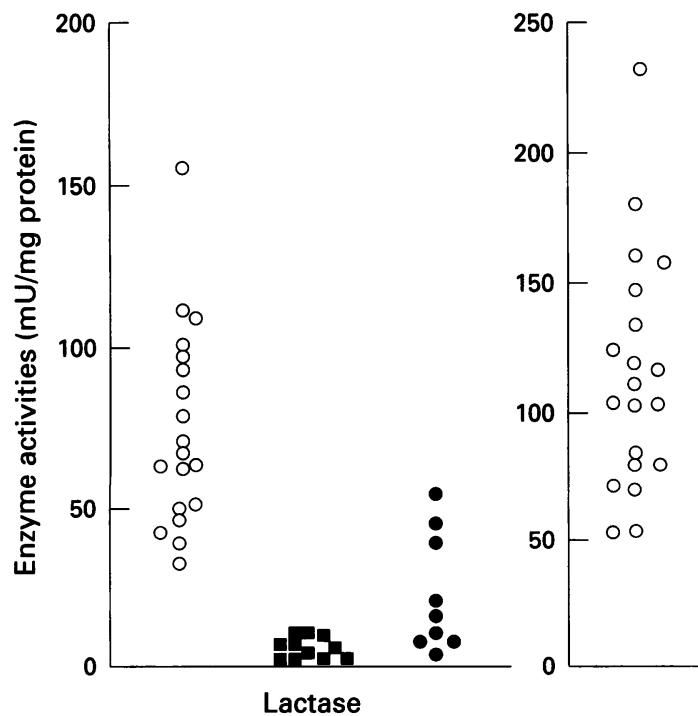

levels were 76 (8), 107 (9), and 34 (2) units/mg protein, respectively. Corresponding values for patients with coeliac disease were, 11 (3), 36 (5), and 11 (2), all of which differed significantly $(p<0.001)$ from controls. Two treated patients had normal activity for all three disaccharidases and three patients each had normal activity of a single disaccharidase.

There was no significant $(p>0 \cdot 1)$ correlation between the lactose/lactulose urine excretion ratio (0-10 hours) and lactase activities by in vitro assay within the control group $(r=0.40)$ or collectively for all the subjects studies $(r=0 \cdot 28)$. Similarly, there was no significant $(p>0.5)$ correlation between sucrose/lactulose and palatinose/ lactulose urine excretion values and in vitro sucrase $(r=0.00)$ and palatinase $(r=0.08)$ activities in the whole group of patients.

Figure 7: In vitro lactase, sucrase, and palatinase activity in jejunal biopsy samples from controls (open circles) and patients with untreated (filled boxes) and treated (filled circles) coeliac disease. 
Despite full clinical recovery with gluten restriction, jenunal biopsy specimens from the treated patients were histologically abnormal showing partial villous atrophy, in keeping with previous studies. ${ }^{21}$

\section{Discussion}

Construction of non-invasive systems for assessing aspects of intestinal function by noninvasive methods such as recovery of orally administered probes in urine calls for attention to the detailed conduct of the test, especially selection of test substances with suitable properties. ${ }^{13}$ An important problem affecting such indirect procedures concerns the distortion of results by adventitious non-mucosal factors such as the rate of gastric emptying and intestinal transit, systemic distribution and metabolism, and renal clearance. Use of the 'differential absorption' principle to overcome such irrelevant variables is intrinsic to the strategy, illustrated in Figure 1, for simultaneous estimation of intestinal lactase, sucrase, isomaltase, and permeability based on the measurement of lactose, sucrose, palatinose, lactulose, and L-rhamnose excreted in urine following oral administration. Such test systems should be based on sound theory, but also shown to be reliable and convenient for clinical and research purposes.

Evaluation of an original method is usually undertaken by demonstrating ability to quantitate a specific function, in this study the activity of intestinal disaccharidases, with respect to the detection of a clinically important defect. This is usually achieved by comparison with previously established techniques. A familiar problem, however, concerns the reliability of test procedures available for reference purposes. Existing methods that depend upon the rise in blood monosaccharide concentration or generation of breath ${ }^{14} \mathrm{C}$-carbon dioxide or hydrogen after oral administration of disaccharide are not only affected by the rate of hydrolysis, but also by the state of intestinal absorption and systemic metabolism of the monosaccharide products. Newcomer and $\mathrm{McGill}^{22}$ have shown that as many as $25 \%$ of subjects without lactase deficiency may have misleadingly 'flat' blood glucose responses to lactose tolerance tests (a rise of less than $20 \mathrm{mg}$ / $100 \mathrm{ml}$ following $50 \mathrm{~g}$ and $100 \mathrm{~g}$ oral lactose). The lactose-hydrogen breath test may become unreliable in the presence of monosaccharide malabsorption, bacterial overgrowth in the upper intestine, or of colonic bacteria incapable of generating hydrogen, and these possibilities require exclusion. ${ }^{23} 24$ In vitro assays performed on a homogenate of intestinal biopsy tissue are generally considered reliable evidence of disaccharidase status, but the measurements obtained relate to the region from which the biopsy tissue was taken and do not necessarily parallel the hydrolytic performance of the whole intestine.

During this study performance of the disaccharide ratio system was assessed by comparing responses obtained from healthy 'normolactasic' volunteers, lactase status being verified by the conventional lactose tolerance test, and also in context with temporary impairment of sucrase activity in healthy volunteers by drug induced $\alpha$-glucosidase blockade where the test distinguishes between the potency of the $\alpha$-glucosidase inhibitors and the duration of drug action. The three $\alpha$-glucosidase inhibitors used for the latter purposes are complex oligosaccharides or, more precisely, pseudo-tetrasaccharides, which have been shown to inhibit intestinal sucrose in vitro and, by indirect methods, in vivo. ${ }^{25}{ }^{26}$ The use and reliability of the disaccharide ratio method combining the use of lactose, sucrose, and palatinose with lactulose reference for the investigation of patients with primary intestinal sucrase-isomaltase, has already been investigated and found to be satisfactory. ${ }^{11} 12$

Subjects with primary hypolactasia had significantly higher urinary lactose/lactulose excretion ratios than those with normal intestinal lactase activity and the range of values (range $0.25-0.78$ ) indicating that most had partial rather than complete lactase deficiency, which would be suggested had the ratio approached $1 \cdot 0$. At the same time the opportunity was taken to compare urinary excretion of galactose with that of lactose in healthy normolactasic and hypolactasic subjects. These results also produced satisfactory discrimination provided they were expressed as galactose/lactose excretion ratios. However well urinary or blood galactose estimations ${ }^{7}$ may discriminate, it must nevertheless be emphasised that galactose intolerance due, for intance, to ethanol intake, ${ }^{27}$ galactose pathway defects or hepatic disease, in addition to impairment of galactose absorption, will render interpretation unreliable while the excretion ratios of lactose/lactulose would remain unaffected. ${ }^{13}{ }^{16}$ Furthermore, abnormal intestinal permeability due, for instance, to villous atrophy or to the effect of non-steroidal anti-inflammatory drugs ${ }^{28}$ will interfere with interpretation by producing a false rise in the galactose/lactose excretion ratio.

The suitability of the disaccharide ratio systems for assessing temporary changes in intestinal disaccharides activity is well illustrated by the results of the study of the three $\alpha$-glucosidase inhibitors, BAY g 5421, BAY m 1099 , and BAY o 1248, reported here. These are shown in Figures 5 and 6 and indicate that the sensitivity and precision of the method is adequate to resolve the quantitative differences in dose response and also differences in the duration of disaccharidase inhibition over a short time interval.

Lactosuria and sucrosuria have long been known to occur in patients with coeliac disease $^{29}$ but the extent to which this was due to increased intestinal (paracellular) permeability or reduced disaccharide hydrolysis has not been clear. ${ }^{13} 30$ Blood glucose responses following the conventional lactose tolerance test generally suggest a high prevalence of lactase deficiency in untreated patients, ${ }^{31}$ but the outcome of this test depends as much upon intestinal monosaccharide transport as upon disaccharidase activity, both of which are often impaired in coeliac disease. ${ }^{31}$ Changes in 
monosaccharide absorption may, similarly, interfere with tests that depend upon the rise in blood level or recovery in urine of galactose, of breath ${ }^{14} \mathrm{CO}_{2}$ derived from ingested ${ }^{14} \mathrm{C}$-lactulose, and also breath hydrogen, which is generated when either unabsorbed monosaccharide or disaccharide enters the colon. ${ }^{78}$ This problem has usually been solved by repeating the test using an equivalent dose of monosaccharide. In vitro assay of intestinal biopsy tissue usually demonstrates the presence of lactase deficiency in coeliac disease regardless of treatment. ${ }^{32}$ The contract between estimates of intestinal disaccharidase activity in coeliac disease by in vitro assay of jejunal tissue and disaccharide hydrolysis assessed in vivo by the disaccharide ratio test is therefore a matter of interest and importance. Ratios of urinary disaccharide excretion, which are not affected by overall variations in monosaccharide transport capacity or permeability to disaccharide, suggest that impairment of intestinal disaccharide hydrolysis may be less prevalent in coeliac disease than suggested by the jejunal disaccharidase assays.

It is of note that although palatinose/lactulose excretion ratios suggest that the in vivo intestinal hydrolysis of palatinose is as efficient as that of sucrose, in vitro assays show that jejunal palatinase activity is much lower than that of sucrase (34 (2) compared with 107 (9) $\mathrm{mU} / \mathrm{mg}$ protein, respectively). Evidently palatinose is a satisfactory substrate for in vivo assessment of intestinal isomaltase activity but, unlike isomaltose, it seems to exert severe substrate inhibition under the conditions of in vivo assay. ${ }^{33}$

In summary, the evidence presented suggests that measurement of urinary hydrolysable/nonhydrolysable disaccharide excretion ratios following oral administration of appropriate disaccharides is a reliable non-invasive technique capable of providing simultaneous quantitative assessment of intestinal lactase, sucrase, and isomaltase activity. We have found the method convenient for studying the dose/ response and temporary duration of action of $\alpha$-glucosidase inhibitors on sucrose hydrolysis, and for the investigation of lactose hydrolysis in subjects with primary (genetic) adult hypolactasia. A study of patients with coeliac disease shows that in most cases impairment of in vivo disaccharide hydrolysis is only moderate.

We thank Bayer UK for the gift of the $\alpha$-glucosidase inhibitors and Tate and Lyle Industries Ltd, Reading, Berks, UK, for the gift of palatinose used in these studies.

1 Menzies IS. Medical importance of sugars in the alimentar tract. In: Grenby TH, Parker KJ, Lindley $M G$, eds. Developments in sweeteners-2. London: Applied Science Publishers, 1983: 89-117.

2 Bedine MS, Bayless TM. Intolerance of small amounts of lactose by individuals with low lactase levels. Gastroenterology 1973; 65: 735-43.

3 Gray GM. Intestinal disaccharidase deficiencies and glucosegalactose malabsorption. In: Stainbury JB, Wyndgaarden JB, Fredrickson DS, eds. The metabolic bases of inherited diseases. 4th ed. New York: McGraw-Hill, 1974: 1526-36.

4 Newcomer AD, McGill DB. Disaccharidase activity in the small intestine. Prevalence of lactase deficiency in
healthy subjects. Gastroenterology 1967; 52: 881-9.
5 Fairclough PD. Digestion and malabsorption and carbohydrate. In: Bouchier IAD, Allan RN, Hodgson HJF, Keighley MRB, eds. Textbook of gastroenterology. London: Balliere Tindall, 1984: 361-7.

6 Isokoski H, Jussila J, Sarna S. A simple screening method for lactose malabsorption. Gastroenterology 1972; 62: 28-32.

7 Grant J, Bezerra JA, Thompson SH, Lemen RJ, Koldovsky O, Udall JN. Assessment of lactose absorption by measurement of urinary galactose. Gastroenterology 1989; 97: ment of

8 Arola $\mathrm{H}$. The strip test for hypolactasia also works without ethanol. Scand $\mathcal{F}$ Gastroenterol 1988; 23: 851-5.

9 Hepner GW. Breath analysis: gastroenterological applications. Gastroenterology 1974; 63: 1250-6.

10 Newman A. Progress report: breath-analysis test in gastroenterology. Gut 1974; 15: 308-23.

11 Maxton DG, Catt SD, Menzies IS. Combined assessment of intestinal disaccharidases in congenital asucrasia by differential urinary disaccharide excretion. $\mathcal{f}$ Clin Pathol 1990; 43: 406-9.

12 Maxton DG, Catt SD, Menzies IS. Intestinal disaccharidases assessed in congenital asucrasia by differential urinary disaccharide excretion. Dig Dis Sci 1989; 34: urinary

13 Menzies IS. Transmucosal passage of inert molecules in health and disease. In: Skadhauge $\mathrm{E}$, Heintze $\mathrm{K}$, eds.
Intestinal absorption and secretion. Lancaster: Falk Intestinal absorption and secretion. Lanca

14 Stewart JS, Pollock DJ, Hoffbrand AV, Hollin DL, Booth CC. A study of proximal and distal intestinal structure and absorptive function in idiopathic steatorrhoea. $Q$ f Med 1967; 26: 425-45.

15 Noone C, Menzies IS, Banatvala JE, Scopes JW. Intestinal permeability and lactulose hydrolysis in human rotaviral gastroenteritis assessed simultaneously by non-invasive differential sugar permeation. Eur $\mathcal{F}$ Clin Invest 1986; 16: 217-25.

16 Bjarnason I, Macpherson A, Hollander D. Intestinal permeability: an overview. Gastroenterology 1995; 108: 1566-81.

17 Menzies IS. Quantitative estimation of sugars in blood and urine by paper chromatography using direct densitometry. $\mathcal{F}$ Chromatogr 1973; 81: 109-27.

18 Menzies IS, Mount JN, Wheeler MJ. Quantitative estimation of clinically important monosaccharides in plasma by rapid thin layer chromatography. Ann Clin Biochem 1978; 15: 65-76.

19 Peters TJ, Batt R, Heath JR, Tilleray J. The microassay of intestinal disaccharidases. Biochem Med 1976; 15: 145-8.

20 Menzies IS, Jenkins AP, Heduan E, Catt SD, Segal MB, Creamer B. The effect of poorly absorbed solute on intestinal absorption. Scand $\mathcal{f}$ Gastroenterol 1990; 25: 1257-64.

21 Slavin G, Sowter C, Robertson S, MacDermott S, Paiton K. Measurement in jejunal biopsy by computer aided microscopy. F Clin Pathol 1980; 33: 254-61.

22 Newcomer AD, McGill DB. Lactose tolerance test in adults with normal lactase activity. Gastroenterology 1966; 50: 340-6.

23 Calloway DH, Murphy EL, Bauer D. Determination of lactose tolerance by breath analysis. Am f Dig Dis 1969; 14: 811-5.

24 Metz G, Jenkins JA, Peters TJ, Newman A, Blendis LM Breath hydrogen as a diagnostic method for hypolactasia. Lancet 1975; i: 1155-7.

25 Walton RJ, Sherif IT, Noy GA, Alberti KGMM. Improved metabolic profiles in insulin-treated diabetics given an
alpha-glucosidase hydrolase inhibitor. $B M \mathcal{F} 1979$; $\mathrm{i}$ : alpha-gluct $220-1$.

26 Hillebrand I, Boehme K, Frank G, Fink H, Berchold F. The effect of the $\alpha$-glucosidase inhibitor Bay $g 5421$ (Acarbose) on meal stimulated elevations of circulating glucose, inulin and triglyceride levels in man. Res Exp Med 1979; 175: 81-6.

27 Salaspuro MP, Kesaniemi YA. Intravenous galactose elimination test with and without ethanol loading in various clinical conditions. Scand $\mathcal{F}$ Gastroenterol 1973; 8: 274-80.

28 Bjarnason I, Williams $\mathrm{P}$, So A, et al. Intestinal permeability and inflammation in rheumatoid arthritis: effects of nonsteroidal anti-inflammatory drugs. Lancet 1984; ii $1171-4$.

29 Weser E, Sleisenger MH. Lactosuria and lactase deficiency in adult coeliac disease. Gastroenterology 1964; 48: 571-8.

30 Muller M, Walker-Smith J, Schmerling DH, Curtius HCH, Prader A. Lactulose: a gas-liquid chromatographic method of determination and evaluation of its use to assess intestinal mucosal damage. Clin Chim Acta 1969; 24: 45-9.

31 Brode S, Gudman-Hoyer E. Incidence and general significance of lactose malabsorption in adult coeliac disease. Scand $\mathcal{f}$ Gastroenterol 1988; 23: 284-8.

32 Peters TJ, Jones PE, Wells G. Analytical subcellular fractionation of jejunal biopsy specimens. Enzyme activities, organelle pathology and response to gluten withdrawal in patients with coeliac disease. Clin Sci Mol Med 1987; 55: 582-92.

33 Dahlquist A. Substrate inhibition of intestinal glucosidases. Acta Chem Scand 1960; 14: 1797-808. 